\title{
Neonicotinoids: Systemic Insecticides and Systematic Failure
}

\author{
Sudarshan Kurwadkar ${ }^{1}$ - Amanda Evans ${ }^{2}$
}

Received: 7 October 2016 / Accepted: 11 November 2016 / Published online: 21 November 2016

(C) Springer Science+Business Media New York 2016

As we celebrate 50 years of publication of the Bulletin of Environmental Contamination and Toxicology (BECT), we are simultaneously discovering that the widespread adoption and use of neonicotinoid compounds originally considered to be environmentally benign can now potentially be considered to be an environmental catastrophe. Imidacloprid, the first generation neonicotinoid, was made commercially available by Bayer AG in 1994. This neurotoxin rapidly became extremely popular due to its high insecticidal activity at low application rate $(0.3 \mathrm{mg} / \mathrm{L})$. In 2004 alone, 131,394 pounds of imidacloprid-based formulations were applied for insecticidal purposes in the State of California (Fossen 2006). In 2016, imidacloprid was the most widely used neonicotinoid in the world (Mathiesen and Goldenberg 2016). The second generation of neonicotinoids (thiamethoxam) was introduced by Syngenta in 2000, and was quickly followed by a third generation of neonicotinoids (dinotefuran), made commercially available by Bayer AG in 2005.

While the generational development and production of neonicotinoids has focused on making these insecticides more potent to their target organisms at very small dosages, their adverse environmental consequences have largely remained overlooked. BECT published its first article on neonicotinoids in 1994, reporting on the persistence of imidacloprid (Rouchaud et al. 1994). Indeed, BECT pioneered reporting on the environmental concerns about

Sudarshan Kurwadkar

skurwadkar@fullerton.edu

1 Department of Civil and Environmental Engineering, California State University, Fullerton, CA, USA

2 Department of Chemistry and Biochemistry, California State University, Fullerton, CA, USA the use of neonicotinoid applications and consequences in agriculture. For example, of the 131 reported instances of neonicotinoid pollution in surface water, nearly $50 \%$ of these studies were published in BECT (Stehle and Schulz 2016). It should be noted that imidacloprid was the first generation neonicotinoid to receive widespread attention for its environmental consequences. The third generation of neonicotinoids, dinotefuran, is several orders of magnitude more soluble in water than the first generation (imidacloprid $610 \mathrm{mg} / \mathrm{L}$; thiamethoxam $4100 \mathrm{mg} / \mathrm{L}$; dinotefuran $39,830 \mathrm{mg} / \mathrm{L})$, in addition to being more potent and persistent (PPDB 2012). While these powerful neonicotinoid properties have definitely helped control pest infestations in agricultural and domestic contexts, our knowledge regarding the environmental consequences and risks to non-target species following their widespread use has sorely lagged behind (Fig. 1).

More than two decades have passed since the introduction of the first generation of neonicotinoid agents. During this time period an improved understanding of the risks that can result from exposure to residual neonicotinoids in non-target species has been established through various studies. In 2008, the Environmental Fate and Effects Division (Environmental Risk Branch V) of the USEPA, acknowledged via a memorandum the potential risks that neonicotinoids present for non-target species such as upland game birds, endangered aquatic invertebrates in both freshwater and marine environments and secondary toxicity to fish due to alteration of food chains (USEPA 2008). It is interesting that, in the same memorandum the USEPA cited disorientation and death of honeybees in France in 1999. These honeybee deaths were attributed to exposure to imidacloprid through foraging on sunflowers grown from imidacloprid coated seeds (USEPA 2008). Since then the pace of scientific understanding regarding 
adverse risk to non-target species including honeybees due to exposure to neonicotinoids has gained momentum. The honeybee deaths were brought to widespread public attention through a 2013 cover page feature in Time magazine, A World Without Bees - Silent Sting (an obvious reference to Rachel Carson's magnum opus Silent Spring that spawn the environmental movement) (Time 2013). However, recognizing and reporting on the risks to non-target species due to exposure to imidacloprid and other neonicotinoids is not enough to ban these compounds at national level. Some published studies lack the rigorous quality of data that is required within the regulatory framework to control or ban the use of an insecticide at national level. Put in the USEPA's words, "Extraordinary regulatory action requires extraordinarily robust evidence that a ban will be effective and no other action will suffice" (USEPA 2016a).

Imidacloprid is now implicated in colony collapse disorder in bees and population reductions in monarch butterflies (Lu et al. 2014; Krischik et al. 2015). Although a number of individual countries have become aware of the risks of using neonicotinoids and have banned their use in agricultural operations (Italy: imidacloprid in 1999; Germany: thiamethoxam in 1998), the United States has not yet taken a stance about neonicotinoid use for agricultural applications. Neonicotinoids have suddenly become a focus of public and regulatory attention due to the reported adverse impacts that they have on non-target species (particularly honeybees) and reports correlating colony collapse disorder to neonicotinoid usage in the European Union (EU). Honeybees actually contribute over $€ 22$ billion annually to European agriculture (European Commission and Press Release 2013; Nelsen 2016); however, between 1985 and 2005, one in six of the EU's pollinating populations have died off as a consequence of agricultural neonicotinoid use. In 2013, the EU placed a 2-year moratorium on the entire class (first-third generations) of neonicotinoids used in the agriculture operations that involve and attract honeybees such as seed treatment, soil application (granules) and foliar treatment on plants and cereals. This moratorium was established upon recommendation from the EU Food Safety Authority, and was based partly on body of evidence and partly under the broad umbrella policy of 'precautionary principle'. This EU moratorium will remain in place until completion of risk assessment and will be reviewed in 2017. The complex nature of risk assessment coupled with critical evaluation of various environmental factors that may be potentially responsible for honeybee deaths, will require considerable time and effort to conclusively identify the cause(s) of colony collapse disorder. It is this lag time that has led to public impatience towards the slow evolution of regulations regarding pesticides. A paucity of robust risk assessment data coupled with the slow nature of regulatory response led the Pesticide Action Network (PAN), a consortium of non-governmental organizations, to initiate a campaign to ban neonicotinoids in agriculture operations. The PAN also urged the USDA to create pesticide free habitat for the pollinators and actively promote expansion of agroecological and pollinator friendly agricultural practices (PAN 2016).

Disturbingly, the very properties that have made neonicotinoid insecticides highly popular, i.e., broad-spectrum neurotoxicity and high insecticidal activity at low concentrations, actually compromise the fundamental principles of the Integrated Pest Management (IPM) program. According to the US Department of Agriculture (USDA 2016), IPM strives to enhance economic benefits and reduce potential detriments to human health and the environment from pests and pest management practices.
Fig. 1 Environmental fate and pathways of exposure to neonicotinoid insecticides: postapplication scenario

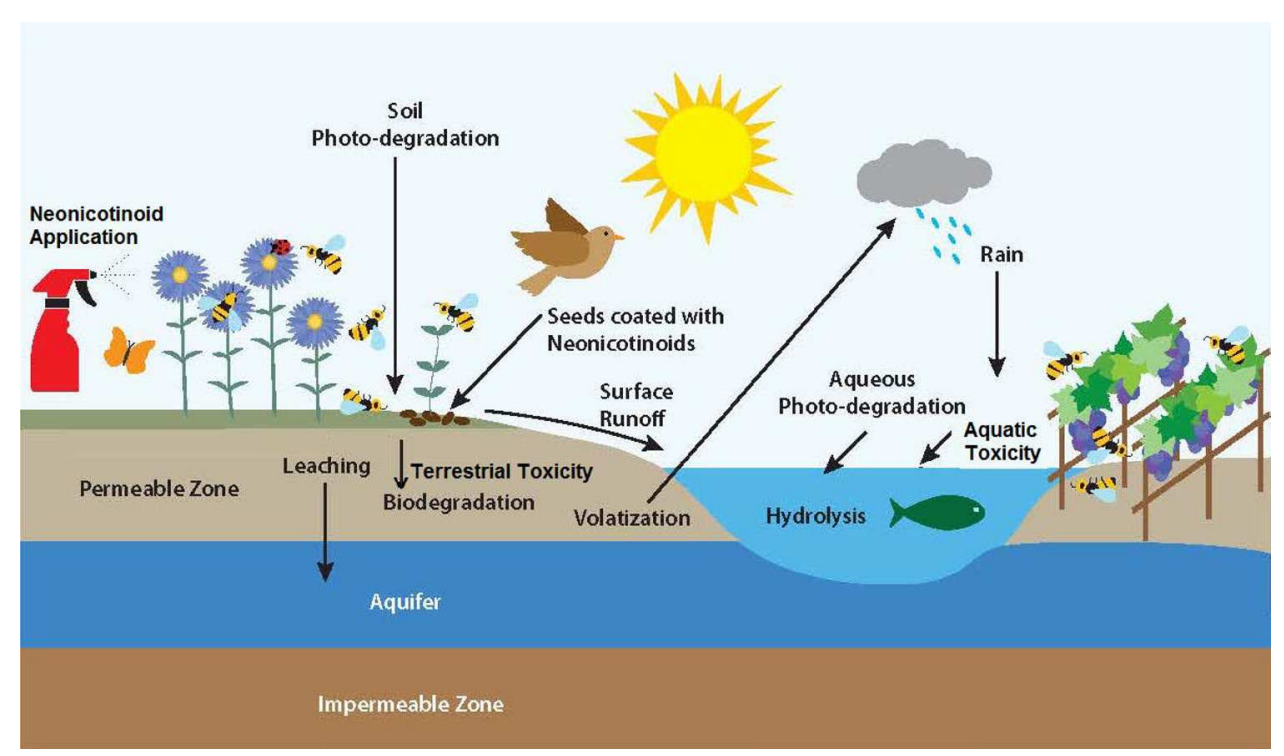


However, neonicotinoids do not fit within this IPM paradigm. Neonicotinoids have greatly reduced pest infestations (e.g., soil insects, termites, and sucking insects such as glassy-winged sharpshooters) in agricultural operations (vineyards, citrus orchards, and vegetable farms) and have contributed greatly to the economic success of such operations. Neonicotinoids have also saved many vineyards from Pierce's disease, which can rapidly destroy vineyard productivity, because these compounds provide a highly effective treatment against Xylella fastidiosa, the etiological agent of Pierce's disease. These examples of the utility of neonicotinoids are certain to make us question economic benefits vs. environmental concerns-but the mounting body of evidence of documented instances of the adverse effects that neonicotinoids can cause in non-target species (honeybees, butterflies and moths, earthworms, bumblebees, solitary bees) also need to be considered and taken into account. Given the widespread usage of neonicotinoids, it is not surprising that these compounds are increasingly detected in various environmental matrices. For example, a recent study published in BECT reported that $89 \%$ of the surface water samples collected from three agricultural regions in California contained imidacloprid, and $19 \%$ of the samples had imidacloprid concentrations that exceeded the USEPA risk threshold for aquatic life of $1.05 \mu \mathrm{g} / \mathrm{L}$ (Starner and Goh 2012). It has also been reported that the occurrence of neonicotinoids in surface water at environmentally relevant concentrations can negatively affect the physiology and survival rates of freshwater and marine animal species (Pisa et al. 2015).

The USA has not yet banned the use of neonicotinoids in agriculture applications. This is because the US Environmental Protection Agency (USEPA) operates under a "risk-based principles" policy: if the risk due to exposure to neonicotinoids is not clearly demonstrated, no efforts will be made to ban the use of neonicotinoids. However, on January 6, 2016, the USEPA formally acknowledged the risk that neonicotinoid exposure presents for honeybees (USEPA 2016b). Through its preliminary risk assessment prepared in collaboration with the State of California's Department of Pesticide Regulation, the USEPA has now established the threshold residual concentration of imidacloprid for honeybees at 25 parts per billion-and has stated that any exposure to imidacloprid above this limit will likely result in decrease in bee populations (USEPA 2016b). Similar conclusions with regard to honeybee neonicotinoid exposure have also been reported by Canada's Pest Management Regulatory Agency (Health Canada 2016; USEPA 2016b). The USEPA has planned to release threshold residual limits of imidacloprid for other non-target species (aquatic and terrestrial animals and plants) by the end of 2016. Risk assessments for pollinators exposed to second- and third-generation neonicotinoids are also planned for release by the USEPA by the end of 2016 .

The question to ponder is: why did it take so long for the EU or the USEPA to act? The systemic nature and broad spectrum activity of neonicotinoids are key characteristics that increase the vulnerability of non-target species. While it is understandable that there is gradual development of scientific understanding of toxicity (particularly mammalian) due to exposure to neonicotinoids, it remains imperative for us to improve our understanding of these compounds and their environmental effects-and to implement regulatory measures that will allow for a more rapid response to potential ecological disasters.

Acknowledgements The authors gratefully acknowledges Ms. Kelly Donovan, Graphic artist at California State University, Fullerton, for assisting with the graphic illustration shown in Fig. 1.

\section{References}

European Commission Press Release (2013) http://europa.eu/rapid/ press-release_IP-13-379_en.htm. Accessed 20 Sept 2016

Fossen M (2006) Environmental fate of imidacloprid. California Department of Pesticide Regulation, Sacramento

Health Canada (2016) Re-evaluation note REV2016-05, re-evaluation of imidacloprid: preliminary pollinator assessment. Pest management regulatory agency. ISSN: 1925-0649 (PDF version) catalogue number: H113-5/2016-05E-PDF (PDF version). http:// publications.gc.ca/collections/collection_2016/sc-hc/H113-52016-5-eng.pdf. Accessed 22 Oct 2016

Krischik V, Rogers M, Gupta G, Varshney A (2015) Soil-applied imidacloprid translocates to ornamental flowers and reduces survival of adult Coleomegilla maculata, Harmonia axyridis, and Hippodamia convergens Lady Beetles, and Larval Danaus plexippus and Vanessa cardui butterflies. PLoS One 10:22

Lu C, Warchol KM, Callahan RA (2014) Sub-lethal exposure to neonicotinoids impaired honey bees winterization before proceeding to colony collapse disorder. Bull Insect 67(1):125-130

Mathiesen K, Goldenberg S (2016) US government says widely used pesticide could harm honeybees. The guardian, https://www. theguardian.com/environment/2016/jan/06/honeybee-populations-decline-pesticides-united-states-epa-study-imidacloprid. Accessed 20 Sept 2016

Nelsen A (2016) EU scientists begin review of ban on pesticides linked to bee declines. The guardian. https://www.theguardian. com/environment/2016/jan/07/eu-scientists-begin-review-banpesticides-linked-bee-declines. Accessed 20 Sept 2016

PAN (2016) Save our bees. http://www.panna.org/our-campaigns/ save-our-bees. Accessed 22 Oct 2016

Pisa LW, Amaral-Rogers V, Belzunces LP, Bonmatin JM, Downs CA, Goulson D et al (2015) Effects of neonicotinoids and fipronil on non-target invertebrates. Environ Sci Pollut Res 22:68-102

PPDB (2012) Pesticide properties database (PPDB). Developed by the Agriculture and Environment Research Unit. University of Hertfordshire, UK. http://sitem.herts.ac.uk/aeru/footprint/en/ index.htm. Accessed 24 June 2013

Rouchaud J, Gustin F, Wauters A (1994) Soil biodegradation and leaf transfer of insecticide imidacloprid applied in seed dressing in sugar beet crops. Bull Environ Contam Toxicol 53:344-350 
Starner K, Goh KS (2012) Detections of the neonicotinoid insecticide imidacloprid in surface waters of three agricultural regions of California, USA. 2010-2011. Bull Environ Contam Toxicol 88(3):316-321

Stehle S, Schulz R (2016) Global insecticide surface water contamination assessment: BECT's contribution in the last five decades. Bull Environ Contam Toxicol 96(5):563-564

Time (2013) A world without bees, August 192013

USDA (2016) https://nifa.usda.gov/program/integrated-pest-management-program-ipm. Accessed 20 Sept 2016

USEPA (2008) Memorandum on EFED problem formulation for the registration review of imidacloprid
EPA-HQ-OPP-2008-0844-0003. https://www.regulations.gov/ document?D=EPA-HQ-OPP-2008-0844-0003. Accessed 6 Nov 2016

USEPA (2016a) https://pesticides.zendesk.com/hc/en-us/ articles/212331717-Why-doesn-t-EPA-ban-the-neonicotinoidpesticides-. Accessed 6 Nov 2016

USEPA (2016b) https://www.epa.gov/newsreleases/epa-releases-firstfour-preliminary-risk-assessments-insecticides-potentially-harmful. Accessed 20 Sept 2016 